\title{
Exigências de lisina digestível para aves de corte da linhagem ISA Label criadas em semiconfinamento
}

\author{
[Digestible lysine requirements for ISA Label broilers reared in free-range system] \\ D.C. Nagib Nascimento ${ }^{1}$, N.K. Sakomura ${ }^{2 *}$, J.C. Siqueira ${ }^{1}$, L.R.B. Dourado ${ }^{1}$, \\ J.B.K. Fernandes ${ }^{2}$, E.B. Malheiros ${ }^{2}$ \\ ${ }^{1}$ Aluno de pós-graduação - FCAV-UNESP - Jaboticabal, SP \\ ${ }^{2}$ Faculdade de Ciências Agrárias e Veterinárias - UNESP \\ Via de Acesso Professor Paulo Donato s/n \\ 14884-900 - Jaboticabal, SP
}

\begin{abstract}
RESUMO
Foram realizados três experimentos para determinar as exigências de lisina digestível para aves da linhagem ISA Label, de ambos os sexos, criadas em semiconfinamento durante as fases: inicial (1 a 28 dias), de crescimento (28 a 56 dias) e final (56 a 84 dias). Em cada experimento, foram utilizadas 480 aves, alojadas em 24 piquetes, cada um contendo abrigo coberto de $3,13 \mathrm{~m}^{2}$ e área de pastejo de $72,87 \mathrm{~m}^{2}$. O delineamento experimental utilizado foi o inteiramente ao acaso, em esquema fatorial 4x2 (níveis de lisina e sexo) com três repetições de 20 aves cada. Os níveis de lisina digestível avaliados foram: 0,850; 0,$970 ; 1,090$ e $1,210 \%$ na fase inicial; 0,$750 ; 0,870 ; 0,990$ e $1,110 \%$ na fase de crescimento e 0,640 ; 0,$760 ; 0,880$ e $1,000 \%$ na fase final. Foram mensuradas as variáveis de desempenho, característica de carcaça, deposição de proteína e gordura corporal, peso e teor de proteína das penas. Com base nos resultados de desempenho, recomendam-se 1,041; 1,006 e 0,760\% de lisina digestível em rações para aves ISA Label nas fases inicial, de crescimento e final, respectivamente.
\end{abstract}

Palavras-chave: frango caipira, aminoácidos, criação alternativa, exigência nutricional

\begin{abstract}
Three assays were carried out to determine digestible lysine requirement for ISA Label, both genders, in free-range system on starter (1 to 28 days), growing (28 to 56 days) e finishing phases (56 to 84 days). A total of 480 birds were distributed into 24 pens, each one composed by shelter $\left(3.13 \mathrm{~m}^{2}\right)$ and pasture $\left(72.87 \mathrm{~m}^{2}\right)$. The experimental design was a completely randomized in factorial arrangement (four levels of lysine and two genders) with three replicates of 20 birds. The digestible lysine levels were 0.85, 0.97, 1.09 , and 1.21\% for starter; 0.75, 0.87, 0.99, and 1.11\% for growing; and 0.64, 0.76, 0.88, and 1.00\% for finishing phases. The analyzed parameters were performance, carcass yield, protein and fat deposition, weight, and protein in the feathers. Based on bird performance the estimated digestible lysine level, was $1.041,1.006$, and $0.760 \%$ for the starter, growing and finishing phases, respectively.
\end{abstract}

Keywords: naked-neck birds, amino acids, broilers, nutritional requirement

\section{INTRODUÇÃO}

Entre os mercados de produtos avícolas, existe um segmento diferenciado, composto por consumidores mais exigentes, que buscam um produto com características diferentes daquelas encontradas no frango convencional criado em sistema intensivo. De acordo com Santos (2004), as aves de crescimento lento apresentam atributos diferenciados na qualidade da carne, como maior textura e coloração da carne mais acentuada, diferente do rosa-pálido das carnes dos frangos industriais. Pesquisas que envolveram frangos de crescimento lento e seu

Recebido em 24 de outubro de 2008

Aceito em 10 de setembro de 2009

*Autor para correspondência (corresponding author)

E-mail: sakomura@fcav.unesp.br 
sistema de produção têm se intensificado com o intuito de garantir uma atividade rentável para os produtores e um produto final de qualidade.

Takahashi et al. (2006) compararam o desempenho e as característica de carcaça de três linhagens específicas para produção colonial e estudaram o efeito do sistema de criação sobre o desenvolvimento das aves. Encontraram diferenças de desempenho e rendimento entre as linhagens e salientaram a importância de escolher a linhagem de acordo com o interesse do mercado. Sobre o sistema de criação, os autores não encontraram diferenças de desempenho entre as aves criadas em sistema confinado ou em piquetes. Contudo, vale ressaltar que, para caracterizar um produto tipo caipira ou colonial, as aves devem ter acesso ao piquete após os 28 dias de vida, com uma área de, no mínimo, $3 \mathrm{~m}^{2}$ de piquete por ave (Instrução..., 1999).

Em relação à nutrição, existem poucos trabalhos sobre as reais exigências nutricionais dessas aves. Mendonça (2005) trabalhou com níveis de energia metabolizável, e Nascimento et al. (2009) com níveis de metionina+cistina digestível para aves de crescimento lento em sistema semiconfinado. Entretanto, para a formulação de dietas balanceadas que proporcionem ótimo desempenho para essas aves, fazem-se necessárias pesquisas que envolvam as demais exigências nutricionais e, também, suas características fisiológicas.

Dentre os principais nutrientes diretamente envolvidos no desenvolvimento das aves, encontra-se a lisina, um aminoácido essencial cujo principal papel fisiológico consiste na síntese de proteínas musculares, a qual está envolvida em menores proporções em outros processos metabólicos (Costa et al., 2001; Lana et al., 2005). Dietas deficientes em lisina podem ter efeitos diretos sobre o desenvolvimento muscular, afetando o desempenho, as características de carcaça e a composição corporal das aves.

O objetivo deste estudo foi determinar as exigências de lisina digestível para aves da linhagem ISA Label de ambos os sexos, criadas em sistema semiconfinado nas fases inicial, de crescimento e final.

\section{MATERIAL E MÉTODOS}

Foram realizados três experimentos no período de 21 de março a 14 de junho de 2006, para determinar as exigências de lisina digestível de aves da linhagem ISA Label, de ambos os sexos, criadas em semiconfinamento nas fases inicial (1 a 28 dias), de crescimento (28 a 56 dias) e final (56 a 84 dias). Em cada fase, foram utilizadas 480 aves (240 machos e 240 fêmeas), distribuídas em 24 piquetes, sendo cada um provido de um abrigo com área de $3,13 \mathrm{~m}^{2}$ e uma área de pastejo de $72,87 \mathrm{~m}^{2}$. O delineamento experimental utilizado foi o inteiramente ao acaso, em esquema fatorial $4 \times 2$ (níveis de lisina digestível e sexo), com três repetições, sendo cada unidade experimental constituída por 20 aves.

$\mathrm{Na}$ fase inicial, as aves alojadas com um dia de idade permaneceram limitadas ao abrigo até o $21^{\circ}$ dia, tendo acesso, a partir de então, à área de pastejo. As aves utilizadas nas fases de crescimento e final foram criadas em galpão convencional até o $28^{\circ}$ e $56^{\circ}$ dia, respectivamente.

Para cada fase, foram formuladas rações basais para atender as exigências nutricionais das aves de acordo com as recomendações do NRC (Nutrient..., 1994), exceto em aminoácidos (Tab. 1). Essas mesmas rações foram suplementadas com L-lisina $\mathrm{HCl}$ em substituição ao ácido Lglutâmico e amido, para possibilitar a obtenção de rações isoenergéticas e isonitrogênicas. Os níveis de lisina digestível foram de 0,$850 ; 0,970$; 1,090 e $1,210 \%$ na fase inicial; 0,$750 ; 0,870$; 0,990 e $1,110 \%$ na fase de crescimento e 0,640 ; 0,$760 ; 0,880$ e $1,000 \%$ na fase final. Os demais aminoácidos foram suplementados em quantidades adequadas para que as relações de aminoácidos digestíveis com a lisina não ficassem abaixo daquelas preconizadas por Rostagno et al. (2005) na proteína ideal.

As variáveis avaliadas em todas as fases foram: ganho de peso (g/ave), consumo de ração (g/ave), consumo de lisina (g/ave) e conversão alimentar. No $84^{\circ}$ dia, foram selecionadas três aves de cada parcela experimental com peso próximo ao peso médio, para avaliar as características de carcaça. 
As deposições de proteína e gordura foram determinadas pela técnica do abate comparativo, sendo os grupos referências de cada fase compostos por nove aves de cada sexo. Ao término de cada experimento, três aves de cada parcela com pesos semelhantes $( \pm 10 \%)$ à média, foram selecionadas, totalizando 72 aves. Após jejum de ração de 24 horas, para o esvaziamento completo do trato digestivo, as aves foram pesadas, abatidas por deslocamento cervical e, após a obtenção de uma amostra representativa das penas de cada ave, depenadas e pesadas novamente. Pela diferença entre o peso em jejum (g) e o peso das aves depenadas (g), obteve-se o peso absoluto das penas $(\mathrm{g})$. $\mathrm{O}$ peso relativo das penas (\%) foi obtido considerando-se o peso das aves em jejum. As amostras das aves depenadas e as das penas de cada ave foram devidamente processadas e analisadas para matéria seca, extrato etéreo e proteína bruta, de acordo com as metodologias descritas por Silva e Queiroz (2002).

As variáveis de desempenho, características de carcaça, composição corporal e das penas foram submetidas a análises de variância, sendo posteriormente realizadas análises de regressão, considerando-se os níveis de lisina digestível da ração como variável independente.

As estimativas dos níveis ótimos de lisina foram obtidas por meio dos modelos Linear Response Plateau (LRP) e/ou polinomial quadrático. Também foi utilizado o procedimento descrito por Baker et al. (2002), no qual o nível ótimo de lisina foi estimado por meio do primeiro ponto de intersecção da curva quadrática com o platô do LRP. As análises estatísticas foram realizadas com o uso do software SAEG (Sistema..., 2001).

Tabela 1. Composição percentual das dietas basais para aves nas diferentes fases experimentais

\begin{tabular}{|c|c|c|c|}
\hline Ingrediente $(\%)$ & Inicial & Crescimento & Final \\
\hline Milho & 65,027 & 69,884 & 75,046 \\
\hline Farelo de soja & 27,978 & 23,657 & 18,918 \\
\hline Óleo de soja & 1,134 & 0,912 & 0,686 \\
\hline Calcário & 1,129 & 1,230 & 1,196 \\
\hline Fosfato bicálcico & 1,713 & 1,305 & 1,113 \\
\hline Sal comum & 0,416 & 0,315 & 0,238 \\
\hline Suplemento mineral $^{1}$ & 0,100 & 0,100 & 0,100 \\
\hline Suplemento vitamínico ${ }^{2}$ & 0,100 & 0,100 & 0,100 \\
\hline DL-Metionina & 0,080 & 0,047 & 0,003 \\
\hline L-Lisina $\mathrm{HCl}$ & 0,000 & 0,000 & 0,000 \\
\hline Ácido L-glutâmico & 2,100 & 2,250 & 2,400 \\
\hline Amido & 0,150 & 0,150 & 0,150 \\
\hline Cloreto de colina $70 \%$ & 0,070 & 0,050 & 0,050 \\
\hline Total & 100,000 & 100,000 & 100,000 \\
\hline \multicolumn{4}{|l|}{ Composição calculada } \\
\hline Proteína bruta (\%) & 19,291 & 17,800 & 16,137 \\
\hline Energia metabolizável (kcal/kg) & 3000 & 3050 & 3100 \\
\hline Cálcio (\%) & 0,940 & 0,870 & 0,800 \\
\hline Fósforo disponível (\%) & 0,420 & 0,340 & 0,300 \\
\hline Sódio $(\%)$ & 0,190 & 0,150 & 0,120 \\
\hline Metionina+cistina digestível (\%) & 0,604 & 0,540 & 0,460 \\
\hline Lisina digestível $(\%)$ & 0,850 & 0,750 & 0,640 \\
\hline Treonina digestível (\%) & 0,615 & 0,560 & 0,500 \\
\hline Arginina digestível (\%) & 1,129 & 1,009 & 0,880 \\
\hline Triptofano digestível (\%) & 0,196 & 0,174 & 0,150 \\
\hline Isoleucina digestível (\%) & 0,706 & 0,636 & 0,560 \\
\hline Valina digestível $(\%)$ & 0,768 & 0,701 & 0,630 \\
\hline
\end{tabular}




\section{RESULTADOS E DISCUSSÃO}

As médias de desempenho e da composição corporal no período de 1 aos 28 dias de idade e o resumo das análises estatísticas para as diferentes variáveis são apresentadas na Tab. 2.

Os níveis de lisina digestível da ração influenciaram todas as variáveis $(\mathrm{P}<0,05)$, exceto o teor de proteínas nas penas (PP). Também observou-se efeito de sexo para todas as variáveis $(\mathrm{P}<0,05)$, com exceção da deposição de gordura (DG).
Apesar de a magnitude das respostas ter variado entre os sexos em todas as variáveis analisadas, a ausência de interação nível de lisina versus sexo indicou que o comportamento das respostas de machos e de fêmeas é semelhante. As estimativas obtidas pelas equações de regressão ajustadas para as variáveis de cada sexo individualmente confirmaram essa hipótese, justificando o ajuste de apenas uma equação para ambos os sexos.

As equações de regressão, os coeficientes de determinação $\left(\mathrm{R}^{2}\right)$ e os níveis de lisina digestível estimados (NLE) são apresentados na Tab. 3.

Tabela 2. Desempenho, deposição de proteína e de gordura corporal, peso relativo e teor de proteína das penas, de aves ISA Label, recebendo níveis crescentes de lisina digestível no período de 1 aos 28 dias de idade

\begin{tabular}{|c|c|c|c|c|c|c|c|c|c|c|}
\hline \multirow{2}{*}{ Variável } & \multirow{2}{*}{ Sexo } & \multicolumn{4}{|c|}{ Nível de lisina digestível (\%) } & \multirow[b]{2}{*}{ Geral } & \multirow{2}{*}{$\begin{array}{l}\text { CV } \\
(\%)\end{array}$} & \multicolumn{3}{|c|}{ Probabilidade de $\mathrm{F}$} \\
\hline & & 0,850 & 0,970 & 1,090 & 1,210 & & & Lis & Sexo & $\begin{array}{l}\text { Lis } x \\
\text { sexo }\end{array}$ \\
\hline \multirow[t]{3}{*}{$\mathrm{CR}(\mathrm{g})$} & $\mathrm{M}$ & 1078,00 & 1120,67 & 1076,67 & 1142,33 & 1104,42 & \multirow{3}{*}{3,40} & \multirow{3}{*}{$<0,01$} & \multirow{3}{*}{$<0,01$} & \multirow{3}{*}{ NS } \\
\hline & $\mathrm{F}$ & 1036,33 & 1076,00 & 963,33 & 1075,33 & 1037,75 & & & & \\
\hline & Geral & $1057,17 \mathrm{BC}$ & $1098,34 \mathrm{AB}$ & $1020,00 \mathrm{C}$ & $1108,83 \mathrm{~A}$ & & & & & \\
\hline \multirow[t]{3}{*}{$\mathrm{CL}(\mathrm{g})$} & $\mathrm{M}$ & 9,16 & 10,87 & 11,74 & 13,82 & 11,40 & \multirow{3}{*}{3,71} & \multirow{3}{*}{$<0,01$} & \multirow{3}{*}{$<0,01$} & \multirow{3}{*}{ NS } \\
\hline & F & 8,81 & 10,44 & 10,50 & 13,01 & 10,69 & & & & \\
\hline & Geral & $8,99 \mathrm{C}$ & $10,66 \mathrm{~B}$ & $11,12 \mathrm{~B}$ & $13,42 \mathrm{~A}$ & & & & & \\
\hline \multirow{3}{*}{$\mathrm{GP}(\mathrm{g})$} & $\mathrm{M}$ & 587,97 & 621,85 & 648,09 & 633,73 & 622,91 & \multirow{3}{*}{3,25} & \multirow{3}{*}{$<0,01$} & \multirow{3}{*}{$<0,01$} & \multirow{3}{*}{ NS } \\
\hline & $\mathrm{F}$ & 529,17 & 571,67 & 566,88 & 575,15 & 560,72 & & & & \\
\hline & Geral & $558,57 \mathrm{~B}$ & $596,76 \mathrm{~A}$ & $607,49 \mathrm{~A}$ & $604,44 \mathrm{~A}$ & & & & & \\
\hline \multirow[t]{3}{*}{$\mathrm{CA}$} & $\mathrm{M}$ & 1,835 & 1,804 & 1,661 & 1,803 & 1,776 & \multirow{3}{*}{3,76} & \multirow{3}{*}{$<0,01$} & \multirow{3}{*}{$<0,05$} & \multirow{3}{*}{ NS } \\
\hline & $\mathrm{F}$ & 1,960 & 1,884 & 1,699 & 1,869 & 1,853 & & & & \\
\hline & Geral & $1,898 \mathrm{~A}$ & $1,844 \mathrm{~A}$ & $1,680 \mathrm{~B}$ & $1,836 \mathrm{~A}$ & & & & & \\
\hline \multirow[t]{3}{*}{$\mathrm{DP}(\mathrm{g})$} & $\mathrm{M}$ & 116,75 & 130,09 & 142,50 & 132,58 & 130,48 & \multirow{3}{*}{5,14} & \multirow{3}{*}{$<0,01$} & \multirow{3}{*}{$<0,01$} & \multirow{3}{*}{ NS } \\
\hline & $\mathrm{F}$ & 105,96 & 117,08 & 122,23 & 117,81 & 115,77 & & & & \\
\hline & Geral & $111,35 \mathrm{C}$ & $123,58 \mathrm{~B}$ & $132,36 \mathrm{~A}$ & $125,19 \mathrm{AB}$ & & & & & \\
\hline DG (g) & $\mathrm{M}$ & 49,22 & 48,89 & 48,54 & 45,07 & 47,90 & & & & \\
\hline & $\mathrm{F}$ & 53,41 & 53,17 & 48,22 & 41,03 & 48,96 & 7,94 & $<0,01$ & NS & NS \\
\hline & Geral & $51,31 \mathrm{~A}$ & $51,03 \mathrm{~A}$ & $48,38 \mathrm{~A}$ & $43,05 \mathrm{~B}$ & & & & & \\
\hline $\mathrm{PR}(\%)$ & $\mathrm{M}$ & 5,99 & 6,34 & 6,64 & 6,23 & 6,30 & 477 & 05 & 11 & NS \\
\hline & F & 6,42 & 6,65 & 6,94 & 6,78 & 6,70 & 4,11 & $<0,0\rangle$ & 01 & \\
\hline & Geral & $6,21 \mathrm{~B}$ & $6,49 \mathrm{AB}$ & $6,79 \mathrm{~A}$ & $6,51 \mathrm{AB}$ & & & & & \\
\hline $\mathrm{PP}(\%)$ & $\mathrm{M}$ & 86,92 & 88,66 & 88,11 & 89,06 & 88,19 & 1.71 & NS & $<0,01$ & NS \\
\hline & $\mathrm{F}$ & 90,56 & 89,53 & 90,69 & 89,81 & 90,15 & $1, / 1$ & NS & $<0,01$ & NS \\
\hline & Geral & 88,74 & 89,10 & 89,40 & 89,44 & & & & & \\
\hline
\end{tabular}

Para cada variável, médias seguidas de letras iguais na linha não diferem entre si $(\mathrm{P}>0,05)$ pelo teste Duncan.

CR: consumo de ração; CL: consumo de lisina digestível; GP: ganho de peso; CA: conversão alimentar; DP: deposição de proteína; DG: deposição de gordura corporal; PR: peso relativo das penas; PP: teor de proteína das penas. CV: coeficiente de variação; NS: não significativo $(\mathrm{P}>0,05)$; $\mathrm{M}$ : machos; $\mathrm{F}$ : fêmeas. 
Tabela 3. Equações ajustadas para consumo de lisina digestível (CL), ganho de peso (GP), conversão alimentar (CA), deposição de proteína (DP), deposição de gordura (DG) corporal e peso relativo (PR) das penas em função dos níveis de lisina digestível (Lis), e coeficientes de determinação $\left(\mathrm{R}^{2}\right)$ e níveis de lisina estimados (NLE) segundo o modelo utilizado

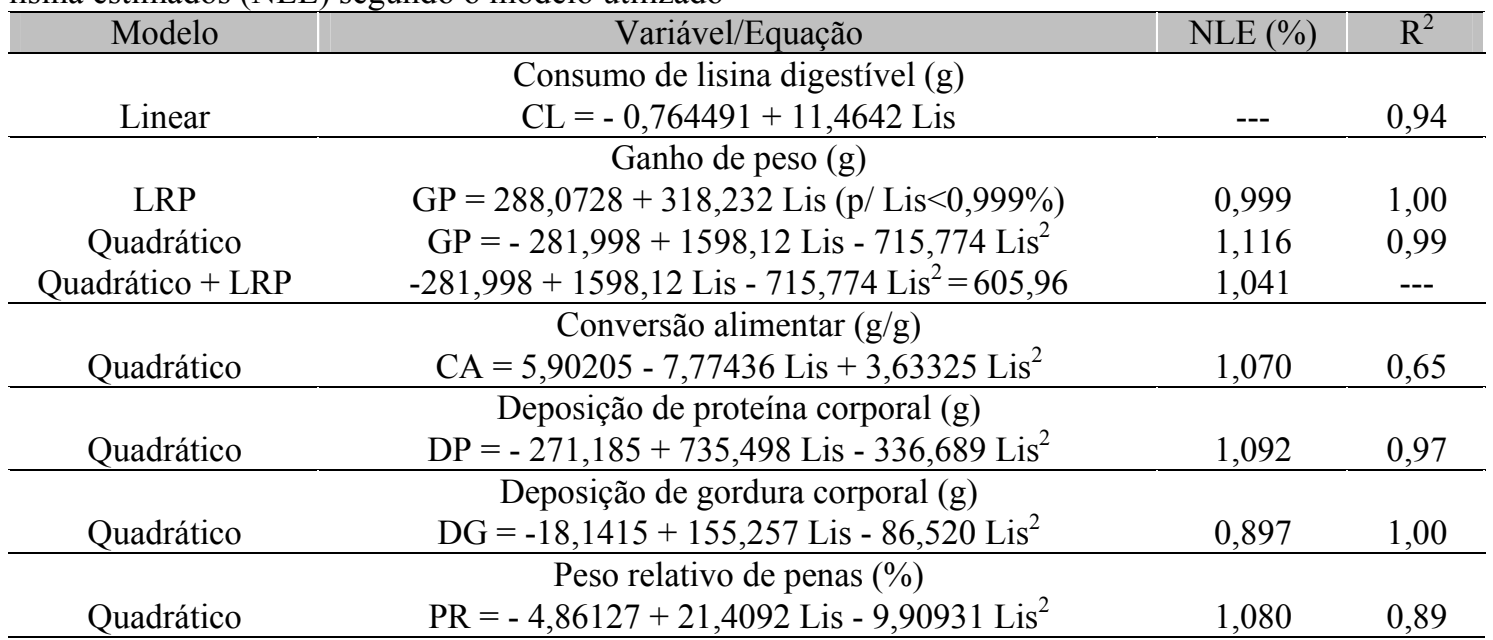

LRP: linear response plateau.

A variação causada pelos níveis de lisina sobre o consumo de ração (CR) das aves não permitiu um ajuste adequado pelos modelos linear, quadrático ou LRP. Já o consumo de lisina digestível (CL) aumentou de forma linear com os níveis de lisina da ração.

As respostas de ganho de peso (GP) foram ajustadas pelos modelos LRP e quadrático. Pelo modelo LRP, o nível ótimo de lisina na ração, estimado pela intersecção da reta ascendente com o platô, foi de $0,999 \%$, podendo ser interpretado como o nível de lisina a partir do qual não haverá incremento no GP das aves.

Por meio da primeira derivada da equação quadrática, foi estimado o nível de lisina digestível de 1,116\%, para maximizar o GP das aves de ambos os sexos. Baker et al. (2002) propuseram a determinação das exigências por meio do primeiro ponto de intersecção da curva quadrática com o platô do LRP, pois, de acordo com Sakomura e Rostagno (2007), existe a possibilidade de subestimativas dos níveis ótimos com o LRP e superestimativas com o modelo quadrático. Com o uso desse procedimento, o nível de lisina digestível na ração adequado para melhorar o GP das aves foi estimado em 1,041\%, correspondente ao consumo de lisina digestível de $11,17 \mathrm{~g}$ por ave, durante o período experimental.
Ao avaliarem os efeitos dos níveis de lisina da ração sobre o GP de frangos Hubbard no período de 1 a 21 dias de idade, Conhalato et al. (1999) estimaram o nível de $1,05 \%$ de lisina digestível como sendo adequado para maximizar o GP das aves, correspondente a um consumo de lisina digestível de $16,65 \mathrm{~g}$ para cada $\mathrm{kg}$ de GP. No presente estudo, o consumo de lisina digestível para cada kg de GP foi estimado em 17,93g para machos e 19,92g para as fêmeas, sugerindo que as aves de crescimento lento apresentam menor eficiência de utilização da lisina para GP quando comparadas às aves de corte de crescimento acelerado.

Para conversão alimentar (CA), foi possível ajustar apenas o modelo quadrático, e estimou-se o nível de 1,070\% de lisina digestível como sendo adequado para minimizar essa variável, correspondente ao consumo de $11,50 \mathrm{~g}$ de lisina digestível por ave durante o período de 1 a 28 dias de idade. Em estudo com frangos de corte no período de 1 a 21 dias de idade, Costa et al. (2001) recomendaram 1,183 e 1,129\% de lisina digestível na ração para minimizar a CA de machos e fêmeas, o que equivale ao consumo estimado de $11,45 \mathrm{~g}$ e $10,16 \mathrm{~g}$ de lisina digestível, respectivamente. Apesar de os resultados terem sido diferenciados com base nas recomendações em porcentagem da ração, observou-se que o consumo de lisina digestível necessário para minimizar a CA das aves de linhagens de 
crescimento acelerado e de crescimento lento é semelhante.

O nível de lisina digestível estimado para maximizar a deposição de proteína corporal das aves na fase inicial foi de $1,092 \%$, obtido com o uso do modelo quadrático. Conhalato et al. (1999), ao trabalharem com frangos de corte Hubbard no período de 1 a 21 dias, relataram que a deposição proteica aumentou até o nível de $1,080 \%$ de lisina digestível. Han e Baker et al. (1993) trabalharam com linhagens de crescimento lento e crescimento acelerado no período de 8 a 22 dias de idade. Os resultados demonstraram que as linhagens apresentaram composição proteica corporal semelhante, sendo a exigência de lisina, expressa em porcentagem da dieta, a mesma para as duas linhagens. Apesar de o presente estudo ter sido realizado com aves de crescimento lento, o nível de lisina recomendado para maximizar a deposição de proteína $(1,092 \%)$ foi próximo ao recomendado por Conhalato et al. (1999) (1,080\%), que trabalharam com linhagem de crescimento acelerado. Essa semelhança sugere que as aves de crescimento lento, nesse caso ISA Label, têm sua composição proteica influenciada pelos níveis de lisina de forma semelhante às aves de corte convencionais no período inicial de vida, conforme observado por Han e Baker (1993).

A deposição de gordura corporal diminuiu a partir do nível de lisina digestível estimado de 0,897\%. Resultados semelhantes foram encontrados por Hurwitz et al. (1998), que relataram que o aumento dos níveis de lisina no período de 1 a 21 dias reduziu a deposição de gordura corporal das aves.

Os níveis de lisina influenciaram o peso relativo das penas (PR) de forma quadrática, isto é, aumentaram até o nível estimado de $1,080 \%$ de lisina digestível na ração.

$\mathrm{Na}$ Tab. 4, encontram-se as médias de desempenho e da composição corporal de aves de ambos os sexos, no período de 28 aos 56 dias de idade, e o resumo das análises estatísticas para as diferentes variáveis.

Houve efeito de sexo $(\mathrm{P}<0,01)$ sobre todas as variáveis avaliadas, com exceção do PR. Os níveis de lisina digestível da ração influenciaram o GP $(\mathrm{P}<0,05)$, o $\mathrm{CR}$, o $\mathrm{CL}$ e o PP $(\mathrm{P}<0,01)$, e não exerceram efeito $(\mathrm{P}>0,05)$ sobre as demais variáveis. Observou-se efeito da interação nível de lisina versus sexo para $\mathrm{CR}, \mathrm{CL}$ e $\mathrm{PP}(\mathrm{P}<0,01)$. Esses resultados demonstraram que $\mathrm{O}$ comportamento das respostas de machos e fêmeas foi diferenciado para essas variáveis.

As equações obtidas para as diferentes variáveis, os coeficientes de determinação $\left(R^{2}\right)$ e os níveis de lisina estimados (NLE) são apresentados na Tab. 5.

Os níveis de lisina da ração influenciaram o CR dos machos de forma linear decrescente, enquanto nas fêmeas o CR foi influenciado de forma quadrática, isto é, reduziu-se até o nível estimado de $1,063 \%$ de lisina digestível na ração. A redução no $\mathrm{CR}$ observada em função do aumento dos níveis de lisina na ração, possivelmente, foi devido à melhoria do perfil geral de aminoácidos da dieta, à medida que a lisina e os outros aminoácidos limitantes foram suplementados nas rações, uma vez que o balanço de aminoácidos da dieta tem efeito direto sobre o consumo voluntário de ração (Boorman, 1979; Gonzales, 2002). O CL das aves de ambos os sexos aumentou linearmente com os níveis de lisina da ração.

As respostas ao GP possibilitaram um ajuste adequado pelos modelos LRP e quadrático. Pelo modelo LRP, o nível ótimo de lisina na ração foi estimado em $0,948 \%$. O ponto de máxima da equação quadrática foi estimado em 1,056\% de lisina digestível para aves de ambos os sexos no período de 28 a 56 dias. O valor estimado pela primeira intersecção da curva quadrática com o platô do LRP foi de $1,006 \%$, assim, este é o nível de lisina digestível considerado mais adequado para melhorar o GP das aves. Esse nível correspondeu ao $\mathrm{CL}$ de $26,54 \mathrm{~g} /$ ave para os machos e de $22,29 \mathrm{~g} /$ ave para as fêmeas, durante o período de 28 a 56 dias de idade. Para o PP, observou-se que as respostas de machos e de fêmeas foram diferenciadas. Para os machos, o modelo quadrático e o LRP proporcionaram ótimos ajustes, sendo o primeiro ponto de intersecção da curva quadrática com o platô do LRP estimado em $0,874 \%$ de lisina digestível na ração. 
Tabela 4. Desempenho, deposição de proteína e de gordura corporal, peso relativo e teor de proteína das penas de aves ISA Label, que receberam níveis crescentes de lisina digestível (Lis) no período de 28 aos 56 dias de idade

\begin{tabular}{|c|c|c|c|c|c|c|c|c|c|c|}
\hline \multirow{2}{*}{ Variável } & \multirow[b]{2}{*}{ Sexo } & \multicolumn{4}{|c|}{ Nível de lisina digestível (\%) } & \multirow[b]{2}{*}{ Geral } & \multirow{2}{*}{$\begin{array}{l}\text { CV } \\
(\%)\end{array}$} & \multicolumn{3}{|c|}{ Probabilidade de $\mathrm{F}$} \\
\hline & & 0,750 & 0,870 & 0,990 & 1,110 & & & Lis & Sexo & $\begin{array}{l}\text { Lis } x \\
\text { sexo }\end{array}$ \\
\hline \multirow[t]{3}{*}{$\mathrm{CR}(\mathrm{g})$} & M & $2648,67 \mathrm{Aa}$ & $2644,33 \mathrm{Ba}$ & $2639,67 \mathrm{Ca}$ & $2635,00 \mathrm{Da}$ & 2641,92 & \multirow{3}{*}{1,01} & \multirow{3}{*}{$<0,01$} & \multirow{3}{*}{$<0,01$} & \multirow{3}{*}{$<0,01$} \\
\hline & $\mathrm{F}$ & $2279,67 \mathrm{Ab}$ & $2273,67 \mathrm{Bb}$ & $2172,33 \mathrm{Db}$ & $2218,00 \mathrm{Cb}$ & 2235,92 & & & & \\
\hline & Geral & 2464,17 & 2459,00 & 2406,00 & 2426,50 & & & & & \\
\hline \multirow[t]{3}{*}{$\mathrm{CL}(\mathrm{g})$} & M & $19,87 \mathrm{Da}$ & $23,01 \mathrm{Ca}$ & $26,13 \mathrm{Ba}$ & $28,99 \mathrm{Aa}$ & 24,50 & \multirow{3}{*}{1,01} & \multirow{3}{*}{$<0,01$} & \multirow{3}{*}{$<0,01$} & \multirow{3}{*}{$<0,01$} \\
\hline & $\mathrm{F}$ & $17,10 \mathrm{Db}$ & $19,78 \mathrm{Cb}$ & $21,51 \mathrm{Bb}$ & $24,40 \mathrm{Ab}$ & 20,70 & & & & \\
\hline & Geral & 18,49 & 21,40 & 23,82 & 26,70 & & & & & \\
\hline \multirow{3}{*}{ GP(g) } & M & 1209,83 & 1233,83 & 1266,17 & 1258,17 & 1242,00 & \multirow{3}{*}{3,52} & \multirow{3}{*}{$<0,05$} & \multirow{3}{*}{$<0,01$} & \multirow{3}{*}{ NS } \\
\hline & $\mathrm{F}$ & 953,67 & 966,50 & 959,17 & 965,17 & 961,12 & & & & \\
\hline & Geral & $1081,75 \mathrm{~B}$ & $1100,16 \mathrm{AB}$ & $1112,67 \mathrm{~A}$ & $1111,67 \mathrm{~A}$ & & & & & \\
\hline \multirow{3}{*}{$\begin{array}{l}\text { CA } \\
F C\end{array}$} & M & 2,189 & 2,143 & 2,086 & 2,095 & 2,128 & \multirow{3}{*}{4,15} & \multirow{3}{*}{ NS } & \multirow{3}{*}{$<0,01$} & \multirow{3}{*}{ NS } \\
\hline & $\mathrm{F}$ & 2,398 & 2,357 & 2,267 & 2,300 & 2,331 & & & & \\
\hline & Geral & 2,293 & 2,250 & 2,176 & 2,197 & & & & & \\
\hline \multirow[t]{3}{*}{$\mathrm{DP}(\mathrm{g})$} & M & 219,05 & 244,21 & 244,51 & 260,89 & 242,16 & \multirow{3}{*}{7,66} & \multirow{3}{*}{ NS } & \multirow{3}{*}{$<0,01$} & \multirow{3}{*}{ NS } \\
\hline & $\mathrm{F}$ & 187,52 & 208,06 & 201,07 & 195,43 & 198,16 & & & & \\
\hline & Geral & 203,28 & 226,13 & 222,80 & 228,16 & & & & & \\
\hline $\mathrm{DG}(\mathrm{g})$ & M & 147,54 & 128,71 & 128,99 & 131,41 & 134,16 & & & & \\
\hline & $\mathrm{F}$ & 134,24 & 122,57 & 117,55 & 113,15 & 119,38 & & & & \\
\hline & Geral & 140,89 & 125,64 & 123,27 & 122,28 & & & & & \\
\hline & M & 5,07 & 5,60 & 5,06 & 6,04 & 5,44 & 1000 & NS & NS & NS \\
\hline PR(\%) & $\mathrm{F}$ & 5,69 & 5,65 & 6,07 & 6,18 & 5,90 & 10,99 & NS & & \\
\hline & Geral & 5,38 & 5,63 & 5,57 & 6,11 & & & & & \\
\hline $\mathrm{PP}(\%)$ & M & $83,18 \mathrm{Db}$ & $89,24 \mathrm{Aa}$ & $88,57 \mathrm{Ba}$ & $88,00 \mathrm{Ca}$ & 87,25 & 60 & 001 & 0.1 & 01 \\
\hline & $\mathrm{F}$ & $89,21 \mathrm{Ca}$ & $89,64 \mathrm{Aa}$ & $89,45 \mathrm{Ba}$ & $88,47 \mathrm{Da}$ & 89,19 & 1,00 & $-0,01$ & $-0,01$ & $<0,01$ \\
\hline & Geral & 86,23 & 89,44 & 89,01 & 88,24 & & & & & \\
\hline
\end{tabular}

Para cada variável, médias seguidas de letras iguais na linha (maiúscula) ou na coluna (minúscula) não diferem entre si (P $>0,05$ ) pelo teste Duncan.

$\mathrm{CR}=$ consumo de ração; $\mathrm{CL}=$ consumo de lisina digestível; $\mathrm{GP}=$ ganho de peso; $\mathrm{CA}=$ conversão alimentar; $\mathrm{DP}=$ deposição de proteína; $\mathrm{DG}=$ deposição de gordura corporal; $\mathrm{PR}=$ peso relativo das penas; $\mathrm{PP}=$ teor de proteína das penas. $\mathrm{CV}=$ coeficiente de variação; $\mathrm{NS}=$ não significativo $(\mathrm{P}>0,05) ; \mathrm{M}=$ machos; $\mathrm{F}=$ fêmeas.

Para o PP das fêmeas, foi possível ajustar apenas o modelo quadrático, sendo o nível ótimo estimado em $0,889 \%$ de lisina digestível na ração. Com base nos resultados de GP e CL dos machos e das fêmeas, foi possível estimar um consumo de lisina digestível de $21,37 \mathrm{~g}$ por $\mathrm{kg}$ de
GP para os machos, e $23,19 \mathrm{~g}$ por kg de GP para as fêmeas.

$\mathrm{Na}$ Tab. 6, estão apresentadas as médias de desempenho e da composição corporal de aves de ambos os sexos, no período de 56 a 84 dias de idade, e o resumo das análises estatísticas. 
Tabela 5. Equações ajustadas para consumo de ração (CR), consumo de lisina digestível (CL), ganho de peso (GP) e teor de proteína das penas (PP) em função dos níveis de lisina digestível (Lis), e coeficientes de determinação $\left(\mathrm{R}^{2}\right)$ e níveis de lisina estimados (NLE) segundo o modelo utilizado

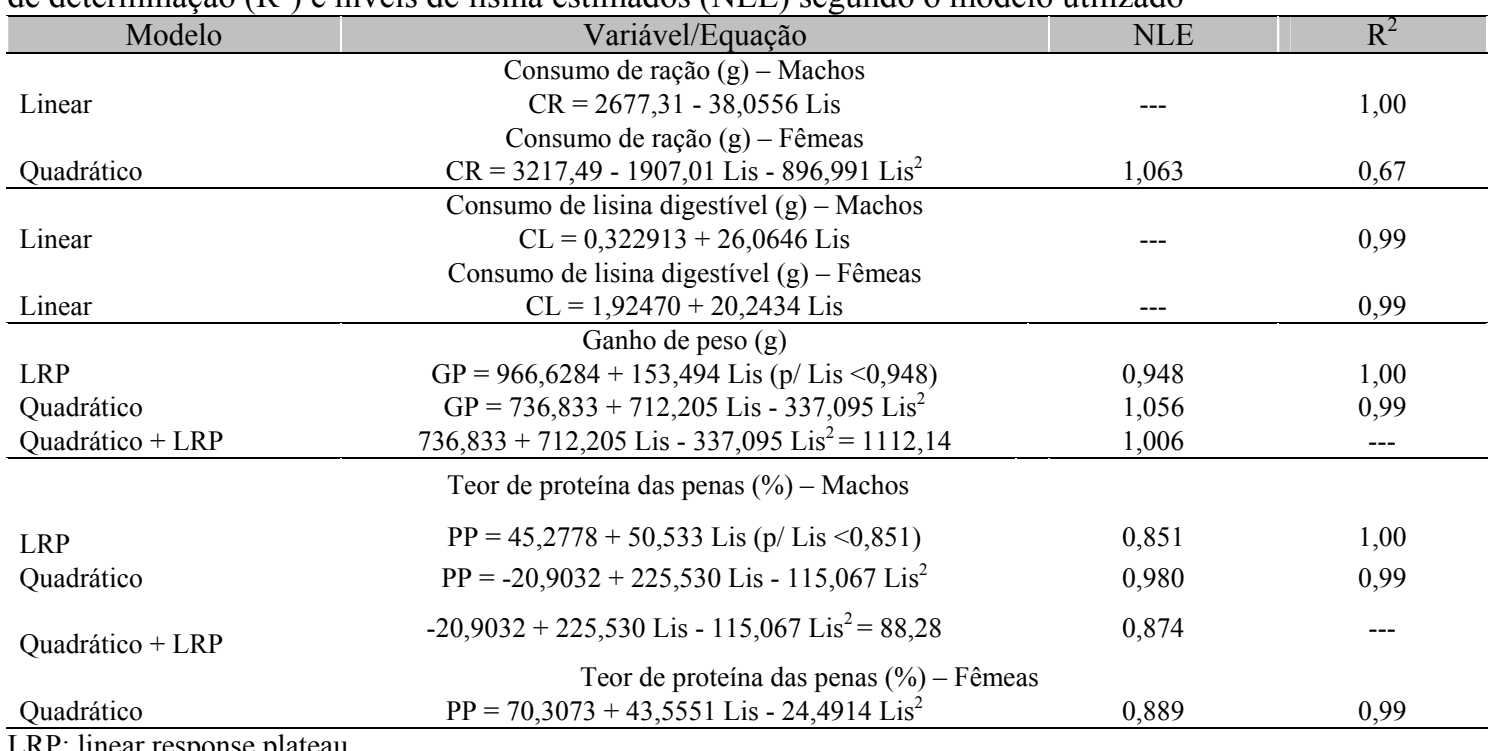

LRP: linear response plateau.

Tabela 6. Desempenho, deposição de proteína e de gordura corporal, peso relativo e teor de proteína das penas de aves ISA Label, que receberam níveis crescentes de lisina digestível (Lis) no período de 56 aos 84 dias de idade

\begin{tabular}{|c|c|c|c|c|c|c|c|c|c|c|}
\hline \multirow[b]{2}{*}{ Variável } & \multirow[b]{2}{*}{ Sexo } & \multicolumn{4}{|c|}{ Nível de lisina digestível (\%) } & \multirow[b]{2}{*}{ Geral } & \multirow{2}{*}{$\begin{array}{l}\text { CV } \\
(\%)\end{array}$} & \multicolumn{3}{|c|}{ Probabilidade de F } \\
\hline & & 0,640 & 0,760 & 0,880 & 1,000 & & & Lis & Sexo & $\begin{array}{l}\text { Lis } x \\
\text { sexo }\end{array}$ \\
\hline \multirow[t]{3}{*}{$\mathrm{CR}(\mathrm{g})$} & $\mathrm{M}$ & 4463,67 & 4201,55 & 4405,67 & 4455,00 & 4381,47 & \multirow{3}{*}{3,17} & \multirow{3}{*}{ NS } & \multirow{3}{*}{$<0,01$} & \multirow{3}{*}{ NS } \\
\hline & $\mathrm{F}$ & 3175,33 & 3136,33 & 3007,33 & 3167,67 & 3121,67 & & & & \\
\hline & Geral & 3819,50 & 3668,94 & 3706,50 & 3811,33 & & & & & \\
\hline \multirow[t]{3}{*}{$\mathrm{CL}(\mathrm{g})$} & $\mathrm{M}$ & $28,57 \mathrm{Da}$ & $31,93 \mathrm{Ca}$ & $38,77 \mathrm{Ba}$ & $44,55 \mathrm{Aa}$ & 35,95 & \multirow{3}{*}{3,35} & \multirow{3}{*}{$<0,01$} & \multirow{3}{*}{$<0,01$} & \multirow{3}{*}{$<0,01$} \\
\hline & $\mathrm{F}$ & $20,32 \mathrm{Db}$ & $23,84 \mathrm{Cb}$ & $26,46 \mathrm{Bb}$ & $31,68 \mathrm{Ab}$ & 25,57 & & & & \\
\hline & Geral & 24,45 & 27,89 & 32,62 & 38,12 & & & & & \\
\hline \multirow{3}{*}{$\mathrm{GP}(\mathrm{g})$} & $\mathrm{M}$ & 1273,33 & 1271,27 & 1269,00 & 1315,00 & 1282,15 & \multirow{3}{*}{3,55} & \multirow{3}{*}{ NS } & \multirow{3}{*}{$<0,01$} & \multirow{3}{*}{ NS } \\
\hline & $\mathrm{F}$ & 822,33 & 856,33 & 824,50 & 853,67 & 839,21 & & & & \\
\hline & Geral & 1047,8 & 1063,80 & 1046,75 & 1084,33 & & & & & \\
\hline \multirow[t]{3}{*}{$\mathrm{CA}$} & $\mathrm{M}$ & 3,507 & 3,305 & 3,474 & 3,388 & 3,418 & \multirow{3}{*}{2,61} & \multirow{3}{*}{$<0,05$} & \multirow{3}{*}{$<0,01$} & \multirow{3}{*}{ NS } \\
\hline & F & 3,865 & 3,663 & 3,643 & 3,712 & 3,712 & & & & \\
\hline & Geral & $3,686 \mathrm{~A}$ & $3,484 \mathrm{~B}$ & $3,558 \mathrm{~B}$ & $3,550 \mathrm{~B}$ & & & & & \\
\hline \multirow[t]{3}{*}{$\mathrm{DP}(\mathrm{g})$} & $\mathrm{M}$ & 273,11 & 278,82 & 307,94 & 260,10 & 280,00 & \multirow{3}{*}{8,71} & \multirow{3}{*}{ NS } & \multirow{3}{*}{$<0,01$} & \multirow{3}{*}{ NS } \\
\hline & F & 182,96 & 184,59 & 202,22 & 204,21 & 193,49 & & & & \\
\hline & Geral & 228,03 & 231,70 & 255,08 & 232,15 & & & & & \\
\hline DG(g) & $\mathrm{M}$ & 190,49 & 169,65 & 217,40 & 201,17 & 194,68 & 1380 & NS & NS & NS \\
\hline & $\mathrm{F}$ & 198,00 & 174,31 & 180,28 & 199,31 & 187,87 & 15,00 & NS & NS & INS \\
\hline & Geral & 194,24 & 171,98 & 198,84 & 200,24 & & & & & \\
\hline $\mathrm{PR}(\%)$ & $\mathrm{M}$ & $5,14 \mathrm{Ba}$ & $4,69 \mathrm{Ca}$ & $4,63 \mathrm{Da}$ & $5,18 \mathrm{Aa}$ & 4,91 & 686 & $<005$ & $<001$ & $<001$ \\
\hline & $\mathrm{F}$ & $6,15 \mathrm{Bb}$ & $5,54 \mathrm{Cb}$ & $6,20 \mathrm{Ab}$ & $4,74 \mathrm{Da}$ & 5,66 & 0,86 & $<0,05$ & $<0,01$ & $<0,01$ \\
\hline & Geral & 5,65 & 5,12 & 5,42 & 4,96 & & & & & \\
\hline $\mathrm{PP}(\%)$ & $\mathrm{M}$ & 86,93 & 87,34 & 87,88 & 86,30 & 87,11 & 0.94 & NS & $<0,01$ & NS \\
\hline & $\mathrm{F}$ & 85,49 & 86,23 & 86,27 & 86,18 & 86,04 & & מ & $-0,01$ & IVS \\
\hline & Geral & 86,21 & 86,79 & 87,08 & 86,24 & & & & & \\
\hline
\end{tabular}

$\overline{\text { Para cada variável, médias seguidas de letras iguais na linha (maiúscula) ou na coluna (minúscula) não diferem entre si (P }>0,05)}$ pelo teste Duncan.

$\mathrm{CR}=$ consumo de ração; $\mathrm{CL}=$ consumo de lisina digestível; $\mathrm{GP}=$ ganho de peso; $\mathrm{CA}=$ conversão alimentar; $\mathrm{DP}=$ deposição de proteína; $\mathrm{DG}=$ deposição de gordura corporal; $\mathrm{PR}=$ peso relativo das penas; $\mathrm{PP}=$ teor de proteína das penas. $\mathrm{CV}=$ coeficiente de variação; $\mathrm{NS}=$ não significativo $(\mathrm{P}>0,05) ; \mathrm{M}=$ machos; $\mathrm{F}=$ fêmeas. 
Houve efeito de sexo $(\mathrm{P}<0,01)$ sobre todas as variáveis avaliadas, com exceção da DG. Os níveis de lisina digestível da ração influenciaram a CA e o $\mathrm{PR}(\mathrm{P}<0,05)$, e o $\mathrm{CL}(\mathrm{P}<0,01)$, e não houve efeito sobre as demais variáveis. Observou-se efeito da interação nível de lisina versus sexo para CL e PR $(\mathrm{P}<0,01)$, evidenciando que o comportamento das respostas de machos e fêmeas foi diferenciado para essas variáveis. $\mathrm{O} C L$ dos machos e das fêmeas aumentou segundo as equações $\mathrm{CL}=-1,48208+$ 45,6547 Lis $\left(\mathrm{R}^{2}=0,98\right)$ e $\mathrm{CL}=0,50200+$ 30,5767 Lis $\left(R^{2}=0,98\right)$, respectivamente.

Considerando-se a CA, não foi possível ajustar nenhum dos modelos propostos, sendo utilizado teste de médias para comparar os resultados. Pelo teste de Duncan, observou-se que o pior resultado de $\mathrm{CA}(\mathrm{P}<0,05)$ foi obtido com a dieta mais deficiente em lisina $(0,640 \%)$. Uma vez que as médias de CA obtidas com os demais tratamentos $(0,760 ; 0,88$ e $1,00 \%)$ foram iguais entre si, recomendou-se o nível de $0,760 \%$ de lisina digestível como sendo o mais adequado para melhorar a CA das aves, correspondendo ao consumo de lisina digestível por ave de $33,22 \mathrm{~g}$ e $23,74 \mathrm{~g}$ para machos e fêmeas, respectivamente, durante o período de 56 a 84 dias de idade.

Os níveis de lisina influenciaram o PR dos machos de forma quadrática, isto é, reduziu-se até o nível estimado de $0,819 \%$ de lisina digestível na ração, segundo a equação: $\mathrm{PR}=$ 16,2390 - 28,4365 Lis + 17,3636 Lis $^{2}(0,99)$. Para o PR das fêmeas, não foi possível o ajuste de nenhum dos modelos propostos, sendo utilizado o teste de Duncan para comparar as médias (Tab. 6).

As médias de rendimento de carcaça e de cortes de aves da linhagem ISA Label de ambos os sexos aos 84 dias de idade e o resumo das análises estatísticas são apresentados na Tab. 7 .

Tabela 7. Rendimentos de carcaça, de peito desossado, de peito com osso, de coxa e de sobrecoxa e porcentagem de gordura abdominal de aves ISA Label que receberam níveis crescentes de lisina digestível aos 84 dias de idade

\begin{tabular}{|c|c|c|c|c|c|c|c|c|c|c|}
\hline \multirow{2}{*}{ Variável } & \multirow{2}{*}{ Sexo } & \multicolumn{4}{|c|}{ Nível de lisina digestível (\%) } & \multirow{2}{*}{ Geral } & \multirow{2}{*}{$\mathrm{CV}(\%)$} & \multicolumn{3}{|c|}{ Probabilidade de F } \\
\hline & & 0,640 & 0,760 & 0,880 & 1,000 & & & Lis & Sexo & $\begin{array}{l}\text { Lis } x \\
\text { Sexo }\end{array}$ \\
\hline \multirow[t]{3}{*}{$\mathrm{RC}(\%)$} & M & 79,69 & 79,78 & 80,19 & 78,45 & 79,53 & \multirow{3}{*}{1,76} & \multirow{3}{*}{$<0,01$} & \multirow{3}{*}{ NS } & \multirow{3}{*}{ NS } \\
\hline & $\mathrm{F}$ & 77,06 & 77,40 & 80,89 & 78,06 & 78,35 & & & & \\
\hline & Geral & $78,37 \mathrm{~B}$ & $78,59 \mathrm{~B}$ & $80,54 \mathrm{~A}$ & $78,26 \mathrm{~B}$ & & & & & \\
\hline \multirow[t]{2}{*}{$\mathrm{PD}(\%)$} & M & 18,52 & 19,27 & 17,85 & 17,86 & 18,38 & \multirow{2}{*}{3,92} & \multirow{2}{*}{ NS } & \multirow{2}{*}{$<0,01$} & \multirow{2}{*}{ NS } \\
\hline & $\begin{array}{c}\mathrm{F} \\
\text { Geral }\end{array}$ & $\begin{array}{l}20,43 \\
19,48\end{array}$ & $\begin{array}{l}20,18 \\
19,72\end{array}$ & $\begin{array}{l}20,51 \\
19,18\end{array}$ & $\begin{array}{l}20,52 \\
19,19\end{array}$ & 18,64 & & & & \\
\hline \multirow[t]{3}{*}{$\mathrm{PO}(\%)$} & M & 25,73 & 25,69 & 24,87 & 24,59 & 25,22 & \multirow{3}{*}{2,54} & \multirow{3}{*}{ NS } & \multirow{3}{*}{$<0,01$} & \multirow{3}{*}{ NS } \\
\hline & $\mathrm{F}$ & 27,32 & 27,27 & 26,69 & 26,55 & 26,96 & & & & \\
\hline & Geral & 26,52 & 26,48 & 25,78 & 25,57 & & & & & \\
\hline \multirow[t]{3}{*}{$\mathrm{CX}(\%)$} & M & 13,78 & 13,93 & 13,92 & 13,98 & 13,90 & \multirow{3}{*}{3,85} & \multirow{3}{*}{ NS } & \multirow{3}{*}{$<0,01$} & \multirow{3}{*}{ NS } \\
\hline & $\mathrm{F}$ & 12,62 & 13,03 & 12,81 & 13,12 & 12,90 & & & & \\
\hline & Geral & 13,20 & 13,48 & 13,37 & 13,55 & & & & & \\
\hline \multirow[t]{3}{*}{ SC (\%) } & M & 15,46 & 15,36 & 15,52 & 15,47 & 15,45 & \multirow{3}{*}{2,39} & \multirow{3}{*}{ NS } & \multirow{3}{*}{ NS } & \multirow{3}{*}{ NS } \\
\hline & $\mathrm{F}$ & 15,54 & 15,49 & 15,45 & 15,35 & 15,46 & & & & \\
\hline & Geral & 15,50 & 15,42 & 15,49 & 15,41 & & & & & \\
\hline \multirow[t]{3}{*}{$\mathrm{GA}(\%)$} & $\mathrm{M}$ & 3,32 & 3,09 & 3,84 & 2,96 & 3,30 & \multirow{3}{*}{18,12} & \multirow{3}{*}{ NS } & & \\
\hline & $\mathrm{F}$ & 5,42 & 4,58 & 5,41 & 4,42 & 4,96 & & & $<0,01$ & NS \\
\hline & Geral & 4,37 & 3,84 & 4,62 & 3,69 & & & & & \\
\hline
\end{tabular}

Para cada variável, médias seguidas de letras iguais na linha (maiúsculas) ou na coluna (minúsculas) não diferem entre si (P $>0,05)$ pelo teste Duncan.

$\mathrm{RC}=$ rendimento de carcaça; $\mathrm{PD}=$ peito desossado; $\mathrm{PO}=$ peito com osso; $\mathrm{CX}=$ coxa; $\mathrm{SC}=$ sobrecoxa; $\mathrm{GA}=$ gordura abdominal. $\mathrm{CV}=$ coeficiente de variação; $\mathrm{NS}=$ não significativo $(\mathrm{P}>0,05) ; \mathrm{M}=$ machos; $\mathrm{F}=$ fêmeas. 
Não se observou efeito da interação nível de lisina na ração versus sexo para nenhuma das características de rendimento avaliadas $(\mathrm{P}>0,05)$, indicando que machos e fêmeas respondem aos níveis de lisina da ração de forma semelhante para essas variáveis.

Houve efeito de sexo sobre todas as características de rendimento $(\mathrm{P}<0,01)$, com exceção do RC e SC.

Os níveis de lisina digestível da ração influenciaram apenas o RC das aves $(\mathrm{P}<0,01)$, que melhorou de forma quadrática até o nível estimado de $0,835 \%$ de lisina digestível na ração, conforme a equação: $\mathrm{RC}=49,4691+72,4497$ Lis - 43,3611 $\mathrm{Lis}^{2}\left(\mathrm{R}^{2}=0,49\right)$. Estes resultados estão de acordo com os encontrados por Costa et al. (2001), que verificaram melhoria no rendimento de carcaça com o aumento dos níveis de lisina da ração, quando trabalharam com frangos de corte de 22 aos 40 e 22 aos 42 dias de idade.

\section{CONCLUSÕES}

Com base nos resultados obtidos para as diferentes fases, recomendam-se, para aves da linhagem ISA Label, de ambos os sexos, níveis de lisina digestível na ração de 1,$041 ; 1,006$ e $0,760 \%$, que equivalem a 0,$347 ; 0,330$ e $0,253 \% /$ Mcal de EM da ração, para as fases inicial, de crescimento e final, respectivamente.

\section{REFERÊNCIAS BIBLIOGRÁFICAS}

BAKER, D.H.; BATAL, A.B.; PARR, T.M. et al. Ideal ration (relative to lysine) of tryptophan, threonine, isoleucine and valine for chicks during the second and third weeks posthatch. Poult. Sci., v.81, p.485-494, 2002.

BOORMAN, K.N. Regulation of protein and aminoacid intake. In: BOORMAN, K.N.; FREEMAN, B.M. (Ed.). Food intake regulation in poultry. Edinburgh: British Poultry Science Ltd, 1979. p.87-126.

CONHALATO, G.S.; DONZELE, J.L.; ROSTAGNO, H.S. et al. Níveis de lisina digestível para pintos de corte machos na fase de 1 a 21 Dias de idade. Rev. Bras. Zootec., v.28, p.91-97, 1999.
COSTA, F.G.P.; ROSTAGNO, H.S.; ALBINO, L.F.T. et al. Níveis dietéticos de lisina para frangos de corte de 1 a 21 e 22 a 40 dias de idade. Rev. Bras. Zootec., v.20, p.1490-1497, 2001.

GONZALES, E. Ingestão de alimentos: mecanismos regulatórios. In: MACARI, M.; FUNLAN, R.L.; GONZALES, E. Fisiologia aviária aplicada a frangos de corte. Jaboticabal, SP: Funep/Unesp, 2002. p.187-199.

HAN, Y.; BAKER, D.H. Effects of sex, heat stress, body weight, and genetic sprain on the dietary lysine requirement of broiler chicks. Poult. Sci., v.72, p.701-708, 1993.

HURWITZ, S.; SKLAN, D.; TALPAZ, H. The effect of dietary protein level on lysine and arginine requirements of growing chickens. Poult. Sci., v.77, p.689-696, 1998.

INSTRUÇÃO normativa ${ }^{\circ} 007$, de 17 de maio de 1999 [do Ministério da Agricultura, Pecuária e Abastecimento]. Diário Oficial da União, Brasília, DF, 19 maio 1999. Seção, 1, p.11.

LANA, S.R.V.; OLIVEIRA, R.F.M.; DONZELE, J.L. et al. Níveis de lisina digestível em rações para frango de corte de 22 a 42 dias de idade, mantidos em ambiente de termoneutralidade. Rev. Bras. Zootec., v.34, p.1624-1632, 2005.

NUTRIENT requirements of poultry. 9.ed. Washington, DC: National Academy of Science, 1994. 154p.

MENDONÇA, O.M. Níveis de energia metabolizável para aves de corte de crescimento lento criadas em sistema semiconfinado. 2005. 114f. Dissertação (Mestrado em Zootecnia) Faculdade de Ciências Agrárias e Veterinárias, Universidade Estadual Paulista, Jaboticabal, SP.

NASCIMENTO, D.C.N.; SAKOMURA, N.K.; SIQUEIRA, J.C. et al. Exigências de metionina+cistina digestível para aves de corte Isa Label criadas em semiconfinamento. Rev. Bras. Zootec., v.38, p.869-878, 2009.

ROSTAGNO, H.S; ALBINO, L.F.T., DONZELE, J.L. et al. Tabelas brasileiras para aves e suínos (composição de alimentos $e$ exigências nutricionais). 2.ed. Viçosa, MG: UFV, 2005. 186p. 
SAKOMURA, N.K.; ROSTAGNO, H.S. Métodos de pesquisa em nutrição de monogástricos. Jaboticabal, SP: FCAV, 2007. $283 \mathrm{p}$.

SANTOS, A.L. Potencial de crescimento, desempenho, rendimento de carcaça e qualidade da carne de diferentes linhagens de frango de corte convencional e tipo caipira. 2004. 95f. Dissertação (Mestrado em Zootecnia) Faculdade de Ciências Agrárias e Veterinárias Universidade Estadual Paulista, Jaboticabal, SP.
SILVA, D.J.; QUEIROZ, A.C. Análise de alimentos: métodos químicos e biológicos. 3.ed. Viçosa, MG: UFV, 2002. 235p.

SISTEMA de análises estatísticas e genéticas SAEG. Versão 9.0. Viçosa, MG: UFV, 2001. $301 p$.

TAKAHASHI, S.E.; MENDES, A.A.; SALDANHA, E.S.P.B. et al. Efeito do sistema de criação sobre o desempenho e rendimento de carcaça de frangos de corte tipo colonial. Arq. Bras. Med. Vet. Zootec., v.58, p.624-632, 2006. 